\title{
Un sistema hidráulico feudal en el valle del Segre: la acequia de Torres
}

\author{
Josep Marfull Oromí \\ Universitat Autònoma de Barcelona \\ josep.marfull@gmail.com
}

\begin{abstract}
Resumen. La conquista de Lleida en 1149 provocó la destrucción de la sociedad andalusí y la construcción de una nueva sociedad feudal. En el proceso de colonización del territorio destacó la actividad constructiva de sistemas hidráulicos constituidos por grandes acequias que tomaban el agua del río Segre. Una de estas acequias es la de Torres de Segre, que, tomando el agua a la altura de la capital, abastece de agua una extensión de unas 1200 ha en el margen izquierdo del río Segre. La investigación que se presenta aplica la metodología de la arqueología hidráulica para definir con el máximo de precisión posible las ampliaciones del espacio irrigado desde el diseño original y cambios en el trazado de la acequia que se han producido en los siglos de funcionamiento del sistema. La documentación ha permitido también seguir la evolución de los derechos señoriales sobre el agua y la organización castral del territorio. Se intenta con esto exponer una parte del proceso de colonización del territorio de Lleida en el contexto del proceso de expansión de la Corona de Aragón.
\end{abstract}

Palabras clave: al-Andalus, colonización feudal, arqueología hidráulica, Lleida

\begin{abstract}
The conquest of Lleida in 1149 caused the destruction on the andalusian society and the construction of a new feudal society. In this process of colonization of the territory should be emphasized the construction of hydraulic systems formed by large channels taking water from the Segre river. One among these channels is the Torres de Segre's one, which, taking water from the river at the height of the city, supplies water to an extension of 1200 ha. in the left bank of the Segre. The research presented here applies the hydraulic archaeology methodology to define with maximum possible accuracy the expansion of the irrigated area from original design and changes on the channel's path along centuries of use. Written documentation has also allowed to follow the evolution of feudal rights on the water and castral organization of the territory. It is intended to expose part of the process of colonization of Lleida territory in the context of the expansion of the Crown of Aragon.
\end{abstract}

Keywords: al-Andalus, feudal colonization, hydraulic archaeology, Lleida

\section{Introducción $^{1}$}

La conquista de Lleida en 1149 fue seguida de un proceso de colonización del territorio por parte de los poderes feudales que tomaron parte en la campaña. El conde de Barcelona, Ramon Berenguer, VI y el de Urgell, Ermengol VI, se dividieron los derechos sobre la ciudad y su cora (ACA, Cancillería, pergaminos de Alfonso I, perg. 260) y repartieron las tierras conquistadas entre las huestes que participaron en la campaña. Este proceso de colonización debe inserirse en la expansión de ambos condados en los decenios anteriores a la toma de Lleida. La madīna Lārida se había convertido en el primer frente de la Frontera Superior de al-Andalus después de las conquistas de Balaguer (1105) y Zaragoza (1118).

A lo largo de la primera mitad del siglo XII, el condado de Urgell colonizó el valle del río Farfanya y consolidó sus dominios hasta Bellvís. Mientras, el condado de Barcelona, en su demarcación de Manresa, llegaba a Sidamon, Arbeca i Tarrés. Con este avance, los feudales

\footnotetext{
${ }^{1}$ Abreviaturas usadas en el texto: ACA (Archivo de la Corona de Aragón), ORM (Órdenes Religiosas Militares), GPSJJ (Gran Priorato de San Juan de Jerusalén), ACL (Archivo Capitular de Lleida), LP (Pergaminos de Lleida), ACB (Archivo Capitular de Barcelona).
} 
se situaban ya a menos de 20 kilómetros de la capital ilerdense. El empuje almorávide solo sirvió para detener la expansión feudal en Corbins (1126), pero con la fragmentación de alAndalus en 1147 se produciría la ofensiva feudal por Tortosa y Lleida (Sabaté, 1998: 16-17). Ésta debe ponerse también en el contexto de la Segunda Cruzada (1147-1149), que propició la llegada de refuerzos del norte de Europa para las conquistas peninsulares. Algunos de ellos incluso participaron en la colonización y se establecieron en los territorios arrebatados a al-Andalus, como documenta Antoni Virgili en Tortosa para normandos de Flandes, Inglaterra y Gales (Virgili, 2010: 91-92).

La campaña de Lleida se inició en marzo de 1149, tres meses después de la caída de Tortosa, y el asedio se alargó hasta el 24 o 25 de octubre, según la fuente (Lladonosa i Pujol, 1974: $122)^{2}$. Pese a que se desconocen detalles de la campaña militar al no conservarse ninguna crónica ni pacto de capitulación (este último sí debió existir), el asedio debió ser duro, según se indica en la carta de población de la ciudad (AML, perg. 1), en la que los condes de Barcelona y Urgell conceden totam civitatem Ilerde, tam constructam quam destructam.

En este artículo se expondrá la colonización de una parte del territorio de Lleida, proceso que supone la "auténtica conquista" y la consolidación del poder feudal sobre un territorio (Virgili, 2010: 79). Se trata de un espacio al sur de la ciudad y en el margen izquierdo del Segre vertebrado por la acequia de Torres, que irriga actualmente los términos municipales de Lleida, Albatàrrec, Montoliu de Lleida, Sudanell y Torres de Segre.

\section{Descripción del trazado de la acequia}

La acequia de Torres es una canalización de poco más de $23 \mathrm{~km}$. que actualmente riega una extensión de aproximadamente 1200 ha. La toma de agua se produce en el Canal de Seròs, una infraestructura construida a principios de siglo XX para la obtención de energía hidroeléctrica. En su curso, discurre entubada por debajo del barrio de Cappont y sigue paralela al camino viejo de Albatàrrec (la antigua carretera Lleida-Tortosa), abasteciendo de agua de riego un espacio del término de Lleida conocido como Sot de Fontanet, situado en un meandro del Segre. Una vez se ha aprovechado el agua para el regadío de este sector, las aguas sobrantes se devuelven al río.

Sigue un tramo de acequia excavado, paralelo al curso del Segre y muy cercano a éste, atravesando el torrente de la Femosa, aunque actualmente no conduce agua y no tiene un uso real. Ya dentro del término municipal de Albatàrrec la acequia vuelve a recibir del agua del canal de Seròs, y sigue su curso por los términos del propio Albatàrrec, Montoliu de Lleida, Sudanell y Torres de Segre. A lo largo del trazado, debe superar diferentes valles y torrentes que desembocan en el río Segre, siendo los más importantes los del río Set (entre Montoliu y Sudanell) i la Vall de Secà, en el tramo final del recorrido. La acequia termina abruptamente antes de llegar a la Vall d'Utxesa o Vall Major, que marca el límite de los términos municipales de Torres de Segre y Aitona.

Se dispone de una descripción del trazado de la acequia fechada el año 1789 que muestra algunas variantes en relación al curso actual. En primer lugar, se mencionan dos puntos de captación distintos, uno en el río y otro en el molino de Cervià. La ubicación de la captación del río se corresponde al azud que fue objeto de una intervención arqueológica durante las obras de acondicionamiento del lecho del Segre a su paso por Lleida en los años

${ }^{2}$ El Fragmentum Historicum del cartulario de Alaó, el cartulario de Roda de Isábena, los Anales Toledanos y el cronicón Barcelonense I sitúan la toma de la ciudad el día 24. Los Gesta Comitum Barcinonensium la fechan el 25. 
90 (García Biosca y Payà Mercé, 1999). La construcción excavada se fechó a principios del siglo XIX, y habría sustituido otra anterior.

De la canalización que recogía las aguas sobrantes del molino de Cervià y se unía a la que tomaba las aguas del río, según la descripción, en la Torre del doctor Rubió, no quedan actualmente restos. La zona ha sido urbanizada en el último medio siglo, y la fotografía aérea del vuelo americano de 1956 no permite seguir el trazado de la acequia, suponiendo que a mediados de siglo XX ésta aún existiese.

Siguiendo el curso de la acequia y aún dentro del término de Lleida, la acequia de Torres estaría abastecida en dos puntos más. El primero, con el agua que salía del molino de Vilanoveta o Sant Anastasi, y el segundo con los sobrantes de la acequia de Fontanet. Ésta última termina justo antes de llegar al torrente de la Femosa, cerca del lugar donde actualmente la de Torres desagua en el río. En este punto, pues, la acequia de Torres hubiera recogido el sobrante de la de Fontanet, llevando esa agua por el tramo que actualmente está seco.

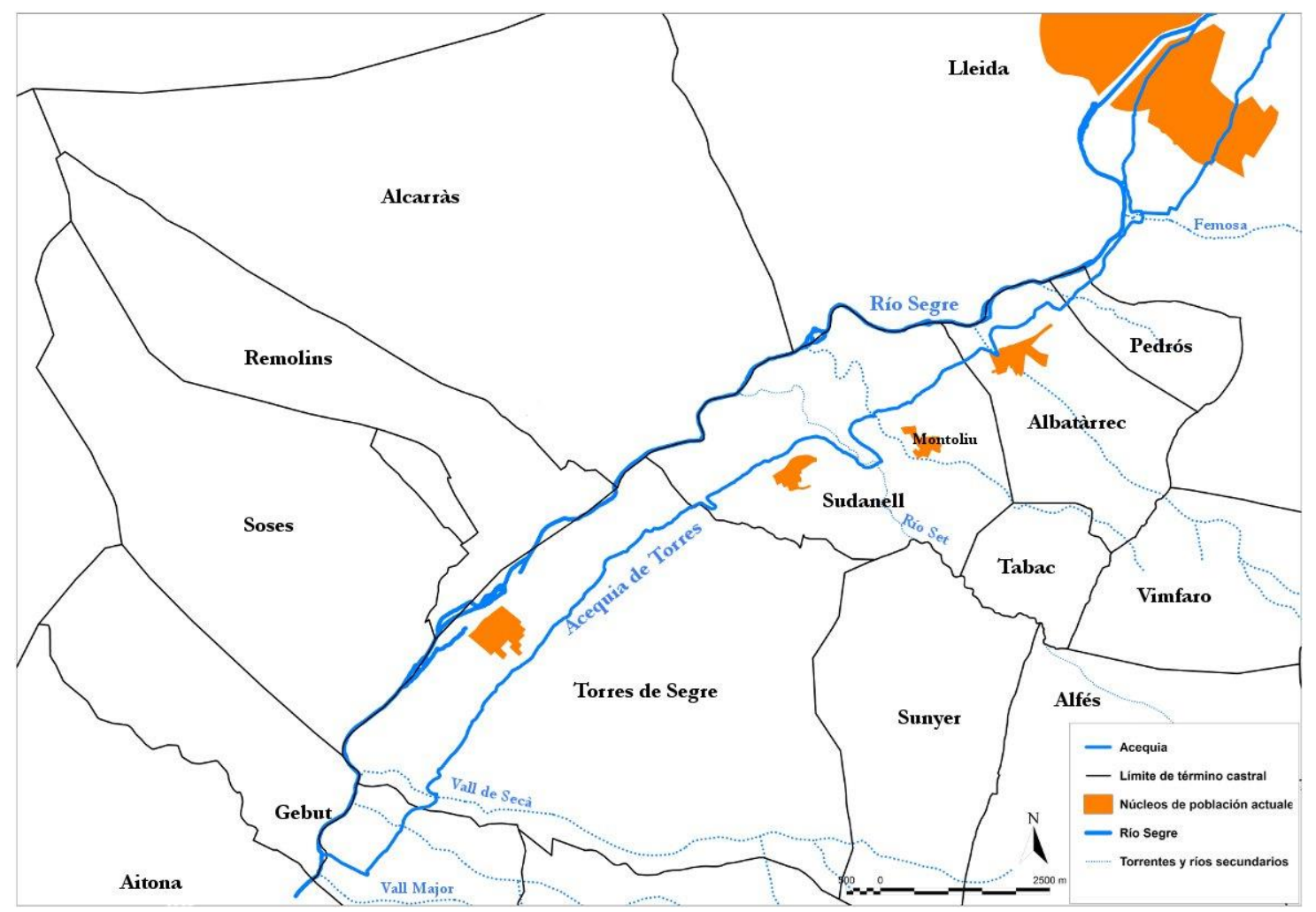

Fig. 1 Plano general del área de estudio

\section{Los términos castrales}

El trazado actual de la acequia de Torres atraviesa lo que en la Baja Edad Media eran, además del término de Lleida, el castrum de Pedrós, el loco de Albatàrrec y los castra de Sudanell, Torres y Gebut. En la actualidad, Pedrós se ha integrado en el municipio de Albatàrrec y Gebut se ha repartido entre Soses y Torres de Segre. Soses integró la parte en el margen derecho del río y Torres la del margen izquierdo, que corresponde al tramo final de la acequia. 


\subsection{Castrum de Pedrós}

El castrum de Pedrós, núcleo hoy en día desaparecido, incluye la parte del término de Albatàrrec más próxima a la ciudad de Lleida. El espacio habitado se encontraría en el Tossal Petit de Pedrós, una elevación al sur de Albatàrrec dónde, pese a no haber restos constructivos, se han localizado fragmentos cerámicos bajomedievales, aún en proceso de estudio. En 1358 (Pons i Guri, 1964: 433) aparece como una posesión de un ciudadano de Lleida, Ramon Janer, y en 1497 ya no es mencionado en el fogatge.(Iglesies, 1991).

\subsection{Loco de Albatàrrec}

Albatàrrec no aparece en ningún momento como castrum, sino como un loco que aparece ya como avecindado a la ciudad de Lleida en 1200 (Botet, 1997). Las menciones en la documentación posterior a la conquista son escasas, y se limitan a mencionar el término como linde en donaciones o ventas (ACA, ORM, carpeta 47, perg. 671). A finales del siglo XIV parece que pertenecía al monasterio de Santa Maria de Bonrepós, tal como consta en el fogatge de 1358 (Pons i Guri, 1964: 422), que fue disuelto en 1462, pasando sus posesiones al de Santes Creus. Sin embargo, no se ha localizado en los fondos documentales de éste último menciones a Albatàrrec.

Parte del actual término municipal podría corresponder a un loco de Alprinano ${ }^{3}$ que linda con el castrum de Sudanell, entre Tabac y Albatàrrec, en 1226 (ACA, ORM, GPSJJ, carp, 47, perg. 663), y dónde Ramon de Sanaüja compra unas tierras en 1237 (ACL, LP 2465). El lugar desaparece de la documentación y no se encuentra más rastro de él.

\subsection{Castrum de Sudanell}

El castrum de Sudanell incluía los actuales términos municipales de Montoliu de Lleida y de Sudanell, con la excepción del sector meridional del primero, que correspondía al castrum de Tabac. Montoliu anexionó el despoblado de Tabac en 1864, con una extensión de 463 jornales y 6 porcas $^{4}$. La primera mención al sitio es de 1168, en el Ordinatio Ecclesie Ilerdensis, dónde Sudanell aparece como una parroquia asociada a la de San Juan de Lleida.

En 1185 Sudanell aparece en el testamento de Guerau de Jorba (Altisent, 1978: 78), al que parece tocó el término en el repartimiento. El castrum es legado a su hija Geralda, casada con Pere de Puigverd, que será quien gestione el feudo. Los hijos de Pere, Berenguer y Guillem, vendieron dos de las torres que conforman el término al Orden del Hospital (ACA, ORM, GPSJJ, carp. 47, perg. 671). El propio Pedro el Católico confirmó a los hospitalarios de la posesión del castrum en 1213 (ACA, ORM, GPSJJ, carp. 47, perg. 662) y aún en 1226 Guillem d'Alcarràs, biznieto de Guerau de Jorba y que según parece conservava ciertos derechos, hace una donación de la Pobla de Sudanell al Hospital (ACA, ORM, GPSJJ, carp. 47, perg. 663).

Dentro del término castral de Sudanell se documentan diferentes torres a lo largo de los siglos XII y XIII. Las de Montoliu, Turre Blancha y Turre Rubea aparecen casi siempre

\footnotetext{
${ }^{3}$ No se ha localizado el topónimo ni se han encontrado restos en el área dónde debería hallarse el asentamiento.

${ }^{4}$ Según la equivalencia del jornal de Lleida (Alsina et al. 1990: 165) a 4358,04 m² la extensión del término de Tabac sería de $2,02 \mathrm{~km}^{2}$.
} 
asociadas al castrum, y conforman el dominio de los descendientes de Guerau de Jorba. Además, el propio Guerau legó al Orden del Hospital el mansum de Iohannes Pina en su testamento (Altisent, 1978: 78) y otra torre, la de Ponç Masip, está entre las posesiones que el obispo de Huesca Jaume Sarroca lega a los templarios en su testamento (P.P.S, 1945). Sería el Orden del Hospital quién acabaría reuniendo la posesión del conjunto del término castral a principios del siglo XIV y lo gestionaría hasta las desamortizaciones del siglo XIX.

La extensión del castrum de Sudanell, incluidas las cuatro turres y el mansum no podía ser superior a los $14 \mathrm{~km}^{2}$. Los términos municipales de Sudanell y Montoliu suman actualmente $16 \mathrm{~km}^{2}$, a los que deben restarse los aproximadamente $2 \mathrm{~km}^{2}$ de Tabac.

La división de un término castral en diferentes distritos es común en el proceso de colonización iniciado en el siglo XI (Sabaté, 1998). En el caso de la zona más próxima a la ciudad, se documentan numerosas almunias o torres, que según Xavier Eritja (1998) habrían tenido su origen en propiedades de4 las élites andalusíes locales. Helena Kirchner (1999) discute este planteamiento dando más importancia a la iniciativa campesina. En algunos casos estas turres acabarían conformando castra, como en el caso de Rosselló, y en otros quedarían integradas dentro de la organización castral. En la zona del Segrià, al norte de la ciudad de Lleida, parece que el número de asentamientos se habría incluso incrementado en la época feudal en relación a los últimos años de dominación andalusí (Sarobe, 2011).

\subsection{Castrum de Torres}

Torres de Segre aparece en la documentación poco después de la conquista de Lleida, en 1153, en una donación de Ramon de Cervera al monasterio de Poblet. Se trata de una parcela en el margen derecho del Segre, lindando con Remolins. A pesar de no disponer de un documento que lo certifique, parece que fueron los Cervera quiénes obtuvieron el castrum en el repartimiento. Como Sudanell, Torres de Segre se menciona también en el Ordinatio Ecclesie Ilerdensis.

Ramon de Cervera vendió su dominio sobre el castrum a tres comerciantes de Lleida de origen occitano, Hug de Blumat, Pere Clavell y Guillem Hug de Tolosa, que compraron los derechos sobre Torres a razón de un tercio para cada uno por un total de 9000 morabetinos en 1227 (ACA, ORM, GPSJJ, carp. 137, perg. 24). La importancia de la burguesía procedente del norte de los Pirineos en la ciudad de Lleida en el siglo XIII viene ya reseñada por Josep Lladonosa (1974: 313-314). En el caso de Torres de Segre, la posesión de los derechos sobre el castrum se mantendría dividida en tres partes hasta 1272.

El tercio de Guillem Hug de Tolosa lo heredaría su hija Guillermina en 1231. De ésta, casada en primeras nupcias con Bernat de Tarascó (otro occitano) y segundas con Arnau d'Artesa, lo legaría a un hijo de este segundo matrimonio llamado también Arnau en 1250. La parte de Hug de Blumat la heredaría su hijo Ferrer, que la vendería en un momento indeterminado antes de 1272 a Constança de Montcada, esposa del conde de Urgell. El tercio restante correspondía en 1272 a Jaume Sarroca, que lo había comprado a Ferrer Clavell, heredero de Bernat (Panadès, Escolà y Bertran, 1983: 61-62).

En mayo de 1272, Martí de Vall-llebrera compró la parte de Jaume Sarroca (ACA, ORM, GPSJJ, carp. 137 perg. 1) y de Constança de Montcada (ACA, ORM, GPSJJ, carp. 137 perg. 25). Solo un año después, Jaume Sarroca adquiría el tercio de Arnau d'Artesa (ACA, ORM, GPSJJ, carp. 137 perg. 14). No se conserva documentación de como Jaume Sarroca adquierió todos los derechos y consiguió la posesión plena del dominio, pero cuando en 
1289 testa en favor del Temple (P.P.S, 1945), no hay ningún elemento que permita entender que Martí de Vall-llebrera conservase aún sus dos tercios y parece, en cambio, que los templarios gozarían de la posesión plena del castrum hasta la disolución de la Orden. A partir de 1312 y hasta las desamortizaciones del siglo XIX Torres de Segre sería una encomienda hospitalaria.

\subsection{Castrum de Gebut}

El centro del castrum de Gebut se encuentra a la derecha del río Segre, en el actual término municipal de Soses. Su término, sin embargo, se extendía a ambos lados del río. En el margen izquierdo del mismo comprendía el espacio situado entre la Vall de Secà i la Vall Major, actualmente perteneciente a Torres de Segre y atravesado por la acequia de Torres.

Gebut aparece como límite sur del término de la ciudad de Lleida en el pacto entre Ramon Berenguer IV y Ermengol VI en 1148 (ACA, Cancillería, pergaminos de Alfonso I, perg. 260). Después de la conquista, formó parte de las posesiones de los Montcada, para acabar integrándose en la encomienda templaria de Torres de Segre mediante donación a principios del siglo XIV (Camps y Martí, 2004: 78-81).

\section{Construcción y gestión del sistema hidráulico (s. XII-XIII)}

La primera mención documental a la acequia es del año 1184, en la concesión del rey Alfonso el Casto a Ramon de Cervera de la facultad de captar agua del río Segre en el lugar que él quisiese entre Castellpagès i Gebut.(ACA, ORM, GPSJJ, carpeta 137, perg. 16). Ramon de Cervera era en ese momento el señor del castrum de Torres de Segre, y la acequia serviría para llevar el agua a sus dominios.

En 1195 Ramon de Cervera cedió parte de los derechos de la acequia al Orden del Hospital. Así, los hospitalarios recibieron en donación la mitad de los derechos de cequiaje y dos tercios sobre los molinos que pudieran construirse, además de un solar en Torres de Segre para construir una casa. El de Cervera se reserva el derecho a regar de forma franca su dominicatura, y los cabezas de familia del lugar, 21 firmantes del documento, obtienen una fanegada franca para cultivar forraje (ACL, LP 2778).

En 1197 hubo un pleito entre Ramon de Cervera y los hospitalarios por un lado y el Temple por otro sobre las aguas sobrantes de los molinos que estos últimos habían construido recientemente en Fontanet. La concesión real del permiso para construir los molinos fecha de 1194 (Sarobe, 1998: doc 624). Los templarios reclamaban haber construido una infraestructura para desviar el agua a dichos molinos y los otro se aprovecharían de este trabajo. Los árbitros, prohombres de la ciudad de Lleida, determinan que el agua puede aprovecharse para la acequia de Torres, a cambio de un censo de 200 sueldos anuales.

El seguimiento de los derechos sobre el agua de la acequia de Torres a lo largo del siglo XIII se hace más complicado. Por un lado, Ramon de Cervera vende su parte de los derechos sobre los molinos a Pere Sassala ${ }^{5}$ por 1000 morabetinos en mayo de 1204 (ACL, Llibre Verd, f.343). En agosto del mismo, el propio Sassala vende al prior de la catedral sus

${ }^{5}$ Los Sassala son una familia con importantes vinculaciones a la gestión dela gua en la Lleida de finales del siglo XII. Pere Ramon Sassala, conocido como Cavassèquia, habría poseído los derechos sobre las acequias de Segrià y Fontanet, en ésta última junto a Guillem de Basella. A principios del siglo XIII vendió todos esos derechos a la universidad de Lleida. (Teira Vilar, 1977: 95-97) $\square$ 
derechos, por los que cobra 1200 morabetinos (ACL, Llibre Verd, f.343v). Con estas dos transacciones, el prohombre leridano obtuvo un beneficio de 200 morabetinos en solo 3 meses.

Por otro lado, en las diferentes transacciones de los derechos del castrum de Torres hay referencias al agua. Cuando Arnau de Artesa da dona sus derechos sobre Torres al procurador de Jaume Sarroca dos días después de la compra (ACL, ORM, GPSJJ, carp. 173 perg. 21), incluye cequia et molendinis de Coniaquera. También en el testamento de Sarroca se mencionan los molinos, pero no la acequia (P.P.S, 1945).

A finales del siglo XIII se documenta un acuerdo entre las universidades de Torres de Segre y Sudanell, por el cual los primeros permiten a los segundos usar el agua, un día a la semana (entre la puesta del sol del sábado y la puesta de sol del domingo) para llenar ocho balsas destinadas a empapar el lino. El resto de la semana, se permite un uso limitado para mantener el nivel de agua, siendo el acequiero el encargado que éste se realice adecuadamente y sin perjuicio a los regantes de Torres (ACB, 1-14-150).

No es, por lo tanto, muy clara la división de los derechos a lo largo del siglo XIII entre los posesores del castrum, el Orden del Hospital que adquirió su parte en 1195 y el priorato de la catedral. En todo caso, los máximos beneficiados acaban siendo los hospitalarios, que son quiénes gestionan la acequia y reciben el sexto de cequiaje a lo largo de la Edad Moderna (ACA, ORM, GPSJJ, leg. 406). De los molinos de Coniaquera no hay referencias más allá de unas últimas menciones en 1325 (ACB, 1-14-149) y 1413 (Delgado Criado, 1982: 127). En la detallada descripción del trazado de la acequia de 1789 no son mencionados (Panadès, Escolà, y Capdevila, 1990).

\section{$5 \mathrm{El}$ diseño original de la acequia de Torres}

Un sistema hidráulico es una infraestructura que requiere una planificación previa, un "diseño original", y debe adecuarse a las características morfológicas del terreno, condicionado por la existencia de pendientes favorables (Barceló, 1989). Sobre esas premisas se ha aplicado la metodología conocida como arqueología hidráulica, vocablo acuñado por el propio Miquel Barceló (1986). El objetivo es el estudio tanto de la infraestructura que transporta el agua como el espacio agrario y el grupo social que construye y gestiona el sistema (Barceló, 1993). Para ello se han venido desarrollando unos procedimientos desde la década de los 90 (Kirchner y Navarro, 1993), que proponen el estudio minucioso del espacio agrario mediante una planimetría precisa contrastado con el análisis de las fuentes documentales y toponímicas. A lo largo de los años esta metodología de ha ido perfeccionando, y en los últimos años se han aplicado técnicas de la geoarqueología y el análisis de paleosuelos para explicar la evolución histórica de un espacio agrario (Puy, Balbo, Virgili, y Kirchner, 2014).

La metodología de la arqueología hidráulica se ha aplicado principalmente a espacios irrigados de origen andalusí de pequeñas dimensiones, hasta 161 catalogados por Eugènia Sitjes (2006). Se han estudiado también sistemas de construcción feudal, como el Canal Reial de Puigcerdà en Cataluña (Kirchner, Vela, y Oliver, 2002); y la Sèquia Major de Vilareal (Guinot y Selma, 2012) en Valencia; diferentes acequias feudales alimentadas por fuentes en Tudela, Baja Navarra (Hernández Charro, 2006) o el impulso de nuevos riegos en el Valle del Cinca por parte de las órdenes militares (Castillón Cortada, 1981). De éstos, los que más pueden compararse a la acequia de Torres por sus características son los del Reino de Valencia, pues se trata de grandes acequias con el punto de captación en un río 
importante y orientadas al regadío. La diferencia primordial es que, si bien en Valencia la iniciativa real fue destacada y los sistemas alimentaban huertas urbanas, la acequia de Torres se construye por iniciativa de Ramon de Cervera, que cuenta con la aprobación del monarca, para irrigar la huerta de un medio rural.

En el área de Lleida existían en época islámica las acequias de Fontanet, en el margen izquierdo del Segre, y Alcarràs, en el derecho (Brufal, 2013). A finales del siglo XII se produciría una ampliación de la acequia de Fontanet, modificando el punto de captación (Eritja, Parés y Sánchez, 2006), y la construcción del Canal de Pinyana en el margen derecho del río, para abastecer tanto la huerta como la propia ciudad (Sol y Torres, 1974). Ninguno de estos sistemas ha sido estudiado con profundidad. Más al sur, aguas abajo del río Segre, se encuentra la acequia de Aitona, de origen andalusí y estudiada por Marta Monjo (2012).

\subsection{Los espacios cultivados}

El dibujo sistemático de una planimetría del conjunto del sistema hidráulico de la acequia de Torres y el estudio de la documentación conservada no permiten definir con precisión un área irrigada original. Se documentan espacios irrigados tanto en Torres de Segre como en Sudanell, sin que se pueda determinar con exactitud su ubicación ni dimensiones.

En Torres de Segre, la donación de Ramon de Cervera al Hospital (ACL, LP 2778) es aceptada por los campesinos de Torres, que se comprometen con el nuevo señor a seguir pagando el censo de la cosecha. El único cultivo del que se tiene constancia para el término son los forrajes, de los cuales cada campesino tiene derecho a una fanegada franca. La escasa documentación relativa a campos de cultivo en el momento inicial de funcionamiento del sistema para este sector explica que no existan referencias a otras plantas.

Tampoco hay dudas de la existencia de espacios de regadío en Sudanell, hasta el punto que la construcción de la acequia provocó el traslado del núcleo habitado del pueblo desde su ubicación original, por debajo de la línea de rigidez, hasta un emplazamiento en una cota superior a la de la acequia y fuera del espacio potencialmente irrigable. La villam novam aparece en la documentación ya en 1195 , en una donación de unas casas quas Guillelmus clericus edificavit in Villanovam de Cudanel (ACL, Llibre Verd, 254r). Uno de los lindes de esta posesión es especialmente significativo. Se trata de la plaça de Berenguer Fiter, un solar que aparece el mismo año como tenedone (ACL, Llibre Verd, f.249v) y ya como domos en 1196 (ACL, Llibre Verd, 251r). Esta villa nueva, pues, se habría parcelado y construido a finales del siglo XII, casi inmediatamente después de la puesta en marcha del sistema hidráulico.

Las menciones a la villa vetera indican un cambio de uso del espacio, que pasa de ser el centro de residencia a convertirse en una zona cultivada e irrigada. El 1200 Pedro de Todenia ofrece al capítulo catedralicio, entre otras posesiones, los derechos que tiene in villa veteri videlicet ortum unum (ACL, Llibre Verd, 251v) para ser aceptado como canónigo. El mismo Pedro, en 1215, dona a censo a Terrena y Arnald Fuster en 1215 unum ortum que est in villa veteri de Cudanel qua había sido de Arsenda Agustina (ACL, Llibre Verd, 253r). Este mismo huerto aparece otra vez en 1223 (ACL, Llibre Verd, 256v), in loco ubi dicitur villa vetera in irriguo, cuando el propio Pedro de Todenia recupera los derechos. Una última mención a los huertos de la Vila Vella se fecha en 1264, cuando se habla de una terra in qua domus prepositure erant in villa vetera (ACL, Llibre Verd, 260r) En este momento, por tanto, el pueblo se habría trasladado definitivamente a lo que es su ubicación actual, quedando el espacio 
ocupado antes por casas para el cultivo de regadío, con una presencia importante de huertos en el sector según la documentación conservada.

Existen dos menciones a huertos anteriores a 1184, fecha de donación de los derechos sobre la acequia. Se trata de dos donaciones en favor de la iglesia de Sudanell en 1181 (ACL, Llibre Verd, 248v y 249). Años más tarde, Pere de Puigverd, señor del castrum, eximiría a la parroquia de pagar cequiaje por estas posesiones. No existe, de todos modos, referencia alguna a una acequia anterior a 1184, y tampoco se ha localizado en la prospección ningún indicio que ésta pudiera haber existido.

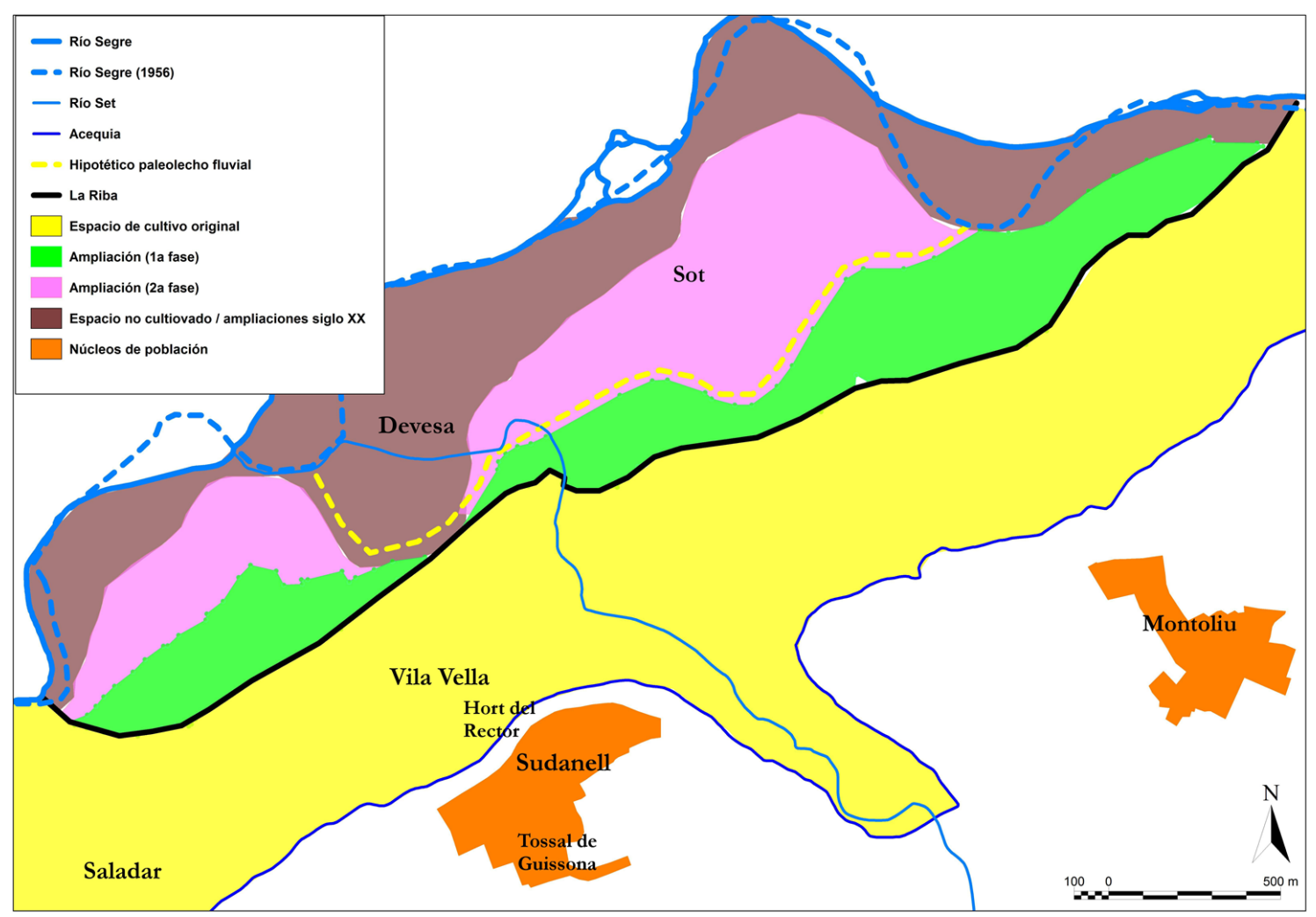

Fig. 2 Espacios de cultivo en Sudanell y Montoliu

Se documentan también en Sudanell un conjunto de ferreginales y linares con un molino contiguo. Un linar, el que Nina Comabella dona a la parroquia (ACL, Llibre Verd, 249) se sitúa en la partida del Saladar, el sector del término de Sudanell limítrofe al de Torres. Contiguos a éste se encuentran los ferreginales de G. Tarascó, donado a la iglesia del lugar por Narbona Tarascona en 1224 (ACL, Llibre Verd, 256) y el de Pere August, donado a Pere de Todènia en 1204 (ACL, Llibre Verd, 255). Cercano a estos campos se halla el molino de Berenguer Fiter, mencionado por primera vez en 1193 (ACL, Llibre Verd, 254), del cual no se ha podido seguir el rastro más allá de principios del siglo XIII.

En el mismo Sudanell, el obispo de Lleida estableció, el 1199, a 10 campesinos con dos fanegadas para cada uno, por un censo anual total de 60 sueldos. Los campos donados a censo lindan con huertos por un lado, un zuto (sot $)^{6}$ por otro y los honores de Bernat

${ }^{6} \mathrm{El}$ término sot designa una tierra baja y arenosa, próxima al río, en la que se plantan árboles y hortalizas. Etimológicamente deriva de un vocablo prerromano, sottu (hoyo, depresión) (DCVB). En la zona de estudio se utiliza comúnmente para designar las partidas de la huerta que cumplen estas características. 
Agustí y Guillem de Vall de Lord por los otros dos. La lectura de los cabreves modernos permite ubicar la zona de huertos justo dónde hoy en día aún de conserva el topónimo de Hort del rector, en la parte de la Vila vella más cercana a la acequia. El linde de una suerte que perteneció a Bernat Agustí entre el Tossal de Guissona, emplazado según los cabreves modernos cerca de los muros del pueblo y del camino de Sarroca, y el río, permite apuntar que la donación episcopal se situaría en la propia Vila Vella o junto a ella.

En ningún caso se hace referencia al posible uso del agua para regadío en otros términos que no sean los de Torres de Segre o Sudanell en el período medieval. De hecho, un acuerdo del comendador de Torres de Segre con la universidad de Lleida para la construcción de un azud en la ciudad en 1325 (1-14-149) especifica claramente y en diversas ocasiones que se trata de llevar agua a los molinos de Coniaquera, Sudanell y Torres de Segre. La primera mención a Albatàrrec es de 1541, cuando el comendador denuncia que los habitantes de dicho pueblo han abierto un partidor sin su permiso (ACA, ORM, GPSJJ, leg. 406)

\section{Ampliaciones del espacio irrigado}

Si bien no han podido definirse con certeza los espacios que formarían parte del diseño original del sistema, sí ha sido posible aislar diferentes zonas y documentarlas como ampliaciones. Se trata, en la mayor parte de los casos, de las zonas más próximas al río o las situadas en los extremos (inicial y final) del trazado de la acequia.

\subsection{El punto de captación}

Anteriormente a la construcción del Canal de Seròs, la acequia tomaba el agua directamente del río Segre, a la altura del que hoy en día es el puente de Pardinyes. Los restos excavados no corresponden a la captación medieval original, sino al punto donde se estableció la construcción de un azud en un acuerdo entre la universidad de Lleida y el comendador de Torres de Segre en XXXX. La obra viene precedida de una necesidad apremiante de agua, pues a lo largo de los siglos XVI y XVI las quejas de los campesinos por el mal abastecimiento de los campos son continuadas.

El punto de captación original o, como mínimo, el más antiguo del que se tiene constancia, es la peixera ${ }^{7}$ (nota) que se construye después del acuerdo entre la universidad de Lleida y el comendador de Torres en 1325. El contencioso, arbitrado por el propio obispo de la ciudad, se resuelve con la autorización por parte de la ciudad de la construcción de la obra a cambio del pago de un censo anual de XXX sueldos. La ubicación de la captación se determina XXX por debajo del puente mayor de la ciudad (el lugar de salida tradicional de la ciudad, conocido hoy en día como Pont Vell. De esta captación construida en el siglo XIV no se han conservado restos.

\subsection{E1 Sot de Fontanet}

Dentro del propio término de Lleida, el único espacio irrigado actualmente por la acequia es el Sot de Fontanet, con una extensión de 55 ha. El propio topónimo es ilustrativo sobre las

\footnotetext{
${ }^{7}$ La peixera es un azud construido para derivar el agua desde el lecho de un río hacia un canal. Etimológicamente proviene de paxaria, derivada de paxum (palo) (DCVB). El hecho que en la documentación de los siglos XI-XII se presente con una forma muy parecida a un derivado de piscis (pez) puede deberse al interés de los señores feudales en dijar los derechos sobre los recursos naturales, y latinizasen una forma más prózima a peix que ya debían utilizar los campesinos de la época para designar unos lugares dónde, además de servir para desviar el agua de un río, eventualmente se practicaba la pesca (Kirchner, Vela, y Oliver, 2002: 21).
} 
características del espacio: se trata de una zona llana, dónde no hay necesidad de practicar aterrazamientos, situada en un meandro del Segre, a una cota ligeramente superior a la del río. Prácticamente todo el espacio está dentro de la zona inundable para un período de retorno de 50 años (cita).

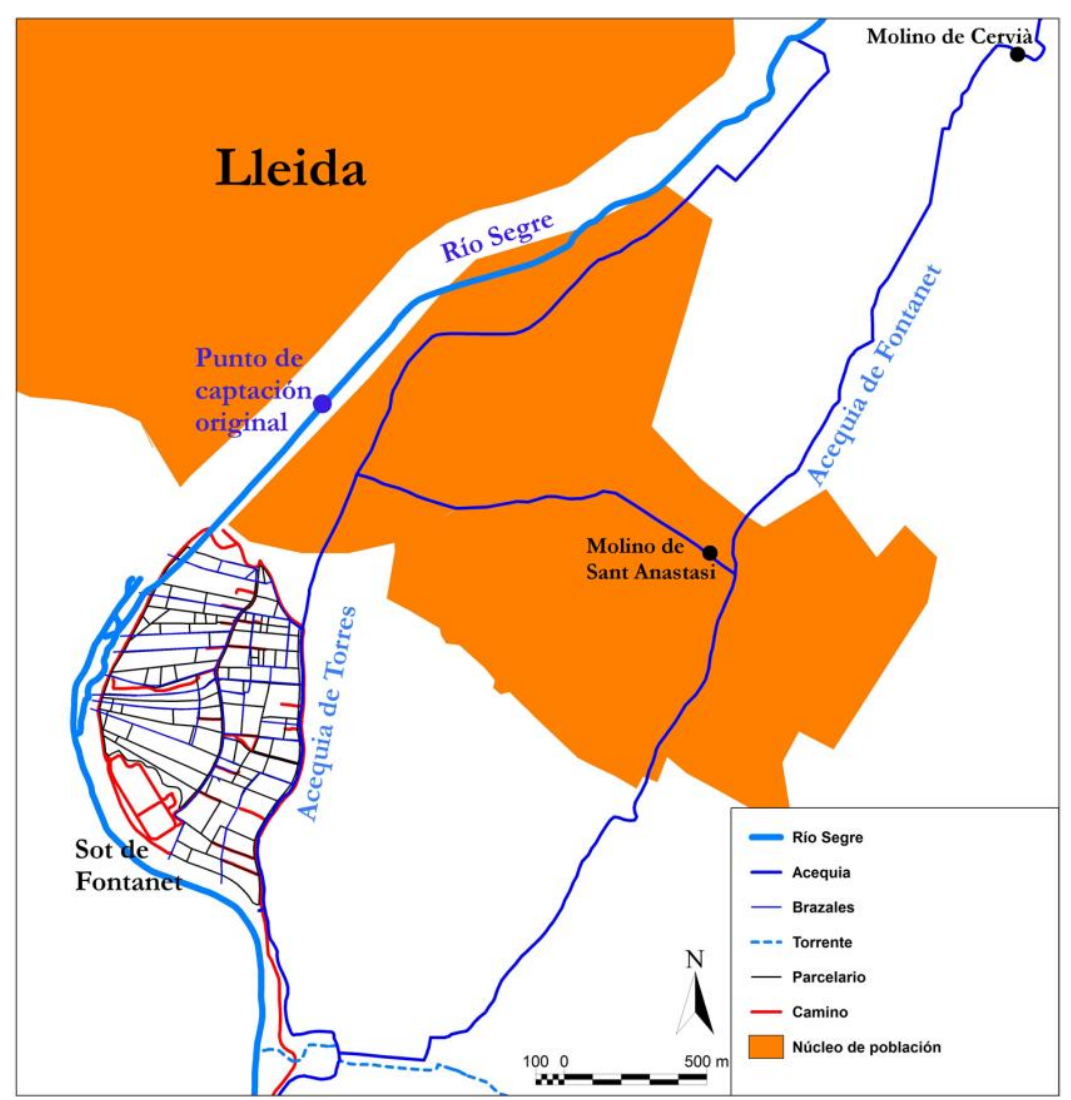

Fig. 2 Vista del tramo de la acequia en el término de Lleida

En el acuerdo sobre la construcción del nuevo punto de captación de la acequia de 1701, una de las cláusulas que impone la ciudad es que se pueda aprovechar el agua en el término de Lleida. Ante las reticencias de los regantes de Torres de Segre, el argumento es que el espacio que podría ser regado en Lleida eran en ese momento arenales y yermos, y que en caso que se cuiltivaran el área sería muy reducida (ACA, ORM, GPSJJ, leg. 406). Anteriormente, en 1431, el río Segre aparece como linde mediante carrera publica que itur versus Tortosa (Delgado Criado, 1982), indicando que no existe un espacio utilizado entre la vía y el río. Las propias características morfológicas del parcelario y los brazales que llevan el agua a cada parcela muestran dos posibles fases de ampliación, separadas por el brazal que cruza longitudinalmente el espacio, que corresponde a un camino actual.

Descartar la posibilidad del regadío en este sector implica asumir que, como mínimo, en los primeros X kilómetros de canalización no fueron aprovechados en el diseño original para el riego, siendo pero útiles para ganar cota y permitir regar un espacio mayor en el tramo subsiguiente. En cambio, sí parece que en este sector se instalaron molinos hidráulicos en fechas muy tempranas. 


\subsection{E1 término de Albatàrrec}

Toda la documentación bajomedieval conservada hace referencia al repartimiento de las aguas entre Torres de Segre y Sudanell, sin mencionar en ningún momento a Albatàrrec (ACB, 1-14-149; ACB, 1-14-150)). Siendo la primera mención del lugar en 1541 (ACA, ORM, GPSJJ, leg. 406), parece que los habitantes de Albatàrrec no tuvieron derechos de uso del agua de la acequia hasta finales de la Edad Media y, por lo tanto, el espacio irrigado correspondiente a este término no formaría parte del diseño original. Son unas 90 ha divididas entre Pedrós y el propio Albatàrrec.

\subsection{La Riba (Montoliu-Sudanell)}

Se conoce con el topónimo de La Riba una línea entre los términos municipales de Montoliu y Sudanell dónde se produce un desnivel importante, que separa las tierras más bajas y cercanas al río, con riesgo de inundación periódica de las más cercanas a la acequia, en una cota más elevada y fuera de cualquier contingencia. Dentro de ese espacio hay dos terrazas diferenciadas, una ligeramente más elevada y otra prácticamente a nivel de río.

Se aprecia un cambio en la morfología del parcelario y los brazales de riego en cada una de estas zonas, con canalizaciones transversales que marcan sin duda fases de ampliación del cultivo. La documentación moderna confirma este hecho, siendo especialmente claro el catastro de 1752 (ACA, ORM, GPSJJ, vol. 222). En éste, se diferencian claramente las parcelas situadas por encima de la Riba (las partidas de Les Planes y Rec de l'Horta) de las que están por debajo (los Sots). Éstas últimas lindan aún con tierras comunes, las más bajas y cercanas al río que se roturarían entre 1752 y 1773, fecha del último cabreve realizado por los Hospitalarios (ACA, ORM, GPSJJ, vol. 219). Las declaraciones de los campesinos indican en todos los casos el origen de la posesión de las tierras, sea la herencia o posesión propia en anteriores censos, sea, en el caso de las tierras más cercanas al río, la reciente roturación. Se conserva aún en un sector de este espacio el topónimo de Devesa, que sugiere un aprovechamiento ganadero de las tierras comunales próximas al río. La documentación conservada no ha dejado rastro de este posible uso.

El sector comprendido entre la Riba y el río tiene una extensión de 175 ha que se extienden entre los términos municipales de Sudanell y Montoliu, y, por lo tanto, dentro de un mismo término castral en el momento de la construcción de la acequia.

\subsection{E1 extremo final: término de Gebut}

En su tramo final el trazado actual de la acequia salva mediante un acueducto la Vall de Secà y la Valleta de les Piles dando un giro de 90 grados para retornar al río justo antes de encontrarse con la Vall Major o d'Utxesa. Es el área perteneciente en la Edad Media al término castral de Gebut.

La prospección hidráulica permite diferenciar la morfología del parcelario y la estructura de los brazales que llevan el agua a los campos en este sector en relación a los del resto del sistema. También el sistema por el que se salvan los valles es diferente. Si en el caso del torrente de la Femosa, el río Set o la Valleta de Sudanell la acequia traza un arco pronunciado siguiendo las curvas de nivel, en los valles dónde se habría producido la ampliación esta curva aprovechando al máximo la pendiente no existe. En cambio, el desnivel se salvan con un acueducto elevado, modificando muy ligeramente el trazado paralelo al río de la acequia. 


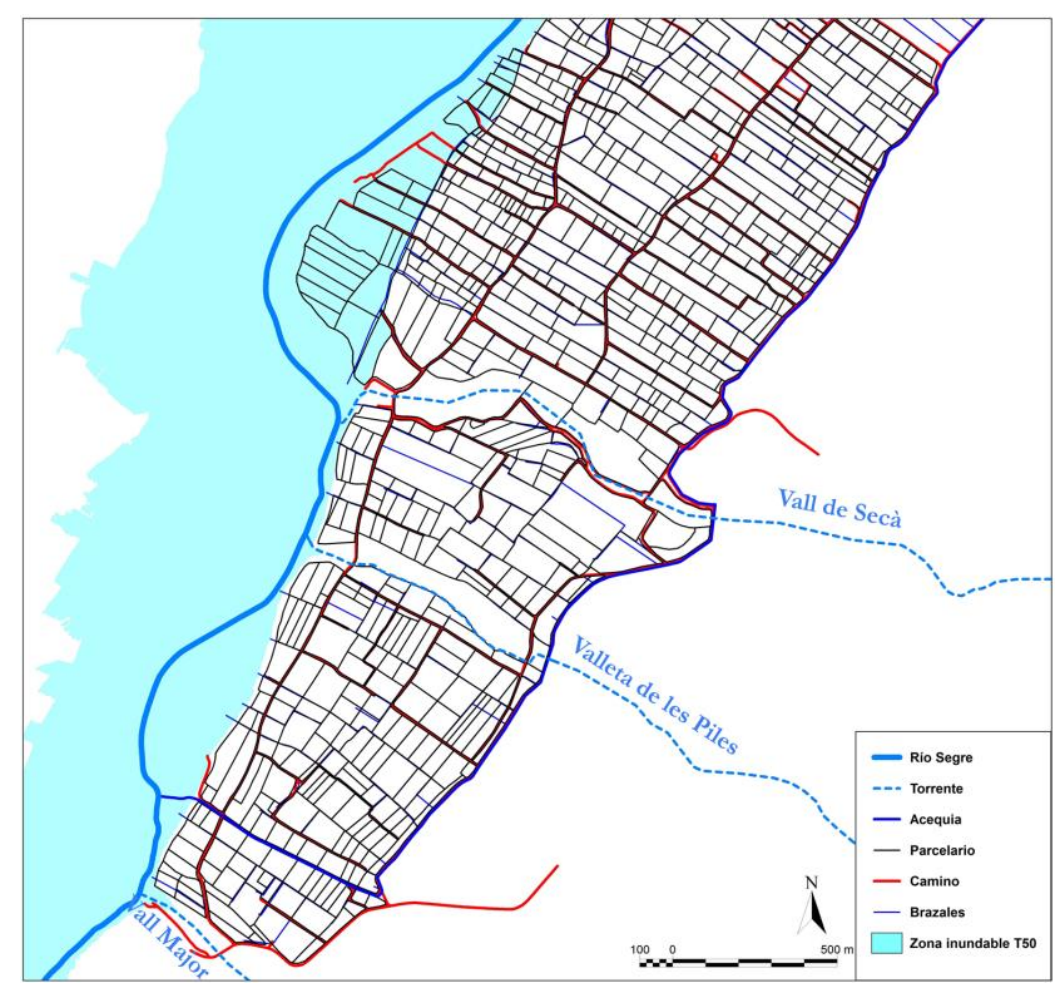

Fig. 4 Tramo final de la acequia

Un cabreve fechado a 1582 (ACA, ORM, GPSJJ, leg. 374) describe este espacio, y menciona límites del parcelario en los diferentes caminos que van a Utxesa, Torres o Aitona, así como en el río Segre. En ningún caso se mencionna acequias u otras estructuras de regadío, como tampoco espacios irrigados. Debe suponerse, pues, que en esta fecha el tramo final de la actual acequia no estaría aún construido, y que el área irrigada finalizaría en la Vall de Secà, límite del término castral de Torres. El espacio ampliado tiene una extensión de 100 ha.

En total, de las 1200 ha de regadío actual, deben restarse unas 420 que corresponden a las diferentes ampliaciones descritas, con lo que la extensión restante que podría formar parte del diseño original es de 780 ha Se trata de un espacio de dimensiones considerables en comparación a otros estudiados, y debe ponerse en el contexto de la población que lo gestionaba para determinar si estas dimensiones pueden corresponderse a la realidad o parte de las cerca de 800 ha deben considerarse también ampliaciones que no ha sido posible detectar.

\section{Dimensiones de población}

No se dispone para la época de estudios demográficos de alcance global, pero para el caso concreto de estudio se pueden usar como referencia los cabezas de familia que firman en los diferentes acuerdos y transacciones de derechos. El lugar para el que se tienen datos más tempranos es Torres de Segre: en la donación de los derechos de la acequia de Torres al Hospital en 1195 (ACL, LP 2778), donde son 21 los vecinos del pueblo que aparecen. La siguiente referencia se halla en el marco de la aceptación de un nuevo señor, cuando Martí de Vall-llebrera compra un tercio del castrum en 1272 . Entonces son 34 los vecinos que juran fidelidad al nuevo señor (ACA, ORM, GPSJJ, carpeta 137, perg. 25). Finalmente, en 1293, en el acuerdo con la universidad de Sudanell sobre el uso del agua de la acequia, hasta 
70 cabezas de familia de Torres de Segre figuran como miembros de la universidad (ACB, 1-14-150).

En el caso de Sudanell, la primera referencia es precisamente dicho documento fechado a 1293, donde son 25 los firmantes. Para finales del siglo XII no hay un documento como el de Torres de Segre, pero alrededor de una veintena de personas aparecen como posesores, sea de casas o de tierras, dentro del castrum.

En ambos casos, pero sobretodo en el de Torres de Segre, se trata de dimensiones relativamente grandes para los procesos colonizadores de la época. De las 64 cartas de población entre 1150 y 1300 conservadas, la mitad no prevén una población mayor de 10 fuegos, $22(34 \%)$ oscilan entre 11 y 21 y sólo en el 16\% de los casos (10 cartas) se prevé que la población será mayor de 30 fuegos. Se trata, en todos los casos, de previsiones, que deben interpretarse a la baja (Virgili, 2010, 97). El hecho de disponer de un sistema hidráulico de las características de la acequia de Torres puede ser la razón que ambos castra se hallen por encima de la media en cuanto a número de habitantes. Para los otros lugares de la zona no se dispone de datos anteriores a los fogatges de mediados de siglo XIV. En 1358, Albatàrrec tenía 17 fuegos (Pons i Guri, 1964: 433), y Montoliu y Pedrós, 19 y 15 respectivamente (Pons i Guri, 1964).

Sumando los castra de Torres de Segre y Sudanell, que incluye la turre de Montoliu, a finales de siglo XII se podría hablar de alrededor de 50 familias, mientras que a finales de siglo XIII la cifra habría aumentado hasta sobrepasar ligeramente el centenar. Para finales del siglo XII corresponderían unas 15 ha por familia, una cifra muy elevada, pero para finales del siglo XIII serían ya algo más de 7 ha por unidad familiar, cifra que es coherente con otros casos de estudio.

En Aitona, el estudio de Marta Monjo (2012: 216) determina un máximo de 45 ha. irrigadas en el siglo XIV, para una población que en 1497 ascendía a 106 fuegos (Iglesies, 1991: 182183), mientras que en Vila-real la superficie irrigada podría haber sido de hasta 793 ha, con 138 beneficiarios documentados tanto en donaciones directas como en los límites de éstas (Guinot y Selma, 2012: 109-110). La proporción entre unidades domésticas y espacio cultivado es de 0,42 ha/familia en el caso de Aitona y de 5,74 ha/familia en el caso de Vilareal. La comparación no debe establecerse tanto con Aitona, una acequia de origen andalusí gestionada en la Baja Edad Media por mudéjares, como con Vila-real, un sistema de construcción feudal posterior a la conquista. La extensión del espacio irrigado pueden considerarse pues, coherentes con las dimensiones de la población que lo gestionaba.

\section{Conclusiones}

La acequia de Torres es un sistema hidráulico proyectado y construido a finales del siglo XII, en el marco de la colonización feudal de un territorio recientemente arrebatado a alAndalus. Se trata de una construcción de dimensiones considerables, con una canalización de XX kilómetros de longitud en un inicio. El análisis de la documentación conservada sugiere que el agua transportada por la acequia se utilizó para el regadío desde el principio, con referencias a espacios irrigados tanto en Sudanell como en Torres de Segre. En cambio, los molinos no se construirían inmediatamente, sino unos pocos años más tarde, entre la donación de Ramon de Cervera al Hospital de 1195 y la venta del propio Cervera a Pere Sassala en 1204. Cabe reseñar también el uso del agua para empapar el lino, documentado ya en 1293. 
El sistema abastece un espacio eminentemente rural, a diferencia de otras acequias construidas entre los siglos XII y XIII en la Corona de Aragón, como son el Canal Reial de Puigcerdà, la acequia de Manresa, la acequia de Vila-real. Las dimensiones de los núcleos de población que gestionaban el espacio hidráulico estaríen en alrededor de 40 familias a finales del siglo XII, ampliándose a cerca de un centenar un siglo más tarde.

Pese a no poder determinar con exactitud cuál habría podido ser el diseño original del sistema hidráulico, sí se han documentado algunas ampliaciones del mismo. En líneas generales, destaca el aprovechamiento del tramo inicial de la acequia para el regadío, ya a finales de la Edad Moderna. También en el tramo final la acequia sería alargada no antes del siglo XVIII, permitiendo irrigar el espacio entre la Vall de Secà i la Vall Major. En la zona intermedia, parece claro que las zonas que se encuentran dentro de las áreas inundables o, incluso, dentro de lo que pueden ser paleolechos del río, serían las últimas en ser cultivadas. En Sudanell, se documenta la roturación de los espacios más cercanos al Segre entre el catastro de 1752 y el cabreve de 1773. Sí parece claro el aprovechamiento del espacio que había ocupado el pueblo de Sudanell, documentado ya como villa vetera a finales de siglo XII, en el sector dónde el topónimo se ha conservado hasta nuestros días.

El espacio restante después de descartar las ampliaciones reseñadas puede parecer muy extenso en comparación al caso de Aitona o a los sistemas de pequeñas alquerías andalusíes. Sin embargo, la relación de poco más de $7 \mathrm{ha} /$ familia, algo por encima de la documentada en Vila-real (5,74 ha/familia), puede considerarse razonable. Es posible, pues, que estas 700 ha. Incluyan todavía alguna ampliación moderna que no se ha podido documentar, pero se acercarían razonablemente a las posibles dimensiones del proyecto hidráulico de finales del siglo XII. El hecho que se produzca un cambio de ubicación de un asentamiento, el caso de Sudanell, dejando libre para el cultivo un espacio por debajo de la línea de rigidez, sugiere también que, sino la totalidad, gran parte del espacio potencialmente irrigado estaba en uso a finales del siglo XII. Este desplazamiento del espacio de residencia marca una preeminencia en la construcción del trazado de la acequia en la organización del espacio, lo que es un gesto autoritario que solo la ejecución de la obra por parte de un señor feudal puede propiciar.

\section{Referencias}

Altisent, A. (1978): Seguint el rastre de Guerau de Jorba i el seu llinatge. Aplec de Treballs, (1), 33-83.

Barceló, M. (1986): La qüestió de l’hidraulisme andalusí. En Les aigües cercades (Els qanat(s) de l'illa de Mallorca), Institut d'Estudis Baleàrics, 9-36.

Barceló, M. (1989): El diseño de espacios irrigados en al-Andalus: un enunciado de principios generales. In El agua en zonas áridas. Arqueología e Historia. Hidráulica tradicional de la provincia de Almería (pp. 13-47). Almeria: Instituto de Estudios Almerienses.

Barceló, M. (1993): Quina arqueologia per al-Andalus? Arqueologia Medieval, (2), 5-16.

Botet, G. (1997): Els Costums de Lleida. Lleida: Ajuntament de Lleida.

Brufal, J. (2013): La medina andalusina de Lleida en el segle XI: Identitat i societat. Rivista dell'Istituto Di Storia dell'Europa Mediterranea, (10), 219-244.

Camps, M. y Martí, E. (2004): Soses a través de la història. Soses. Ajuntament de Soses.

Castillón Cortada, F. (1981): Politica hidráulica de templarios y sanjuanistas en el Valle del Cinca (Huesca). Cuadernos de Historia Jerónimo Zurita, 35-36, 381-445. 
DCVB. Diccionari català-valencià-balear: inventari lexicogräfic i etimològic de la llengua catalana en totes les seves formes literàries $i$ dialectals. http://dcvb.iecat.net/

Delgado Criado, B. (1982): El Cartulario del Colegio Universitario de Santa Maria de Lérida (13761564). Barcelona: Universitat de Barcelona.

Eritja Ciuró, X., Plana i Parés, P., \& Sánchez Pagès, M. (2006): Records d’un rec urbà : la sèquia de Fontanet $i$ el moli de Sant Anastasi o de Vilanoveta. Lleida: Ajuntament de Lleida

Eritja, X. (1998): De l'Almunia a la Turris: organització de l'espai a la regió de Lleida (segles XI-XII) (p. 100). Lleida: Universitat de Lleida.

Garcia Biosca, J. E. y Payà Mercé, X. (1999): Excavacions a l'antic barri de Cappont i a la sèquia de Torres. Iltirda Lleida: Ajuntament de Lleida, Regidoria de Cultura.

Guinot, E. y Selma, S. (2012): La construcción del paisaje en una huerta feudal: la Séquia Major de Vila-Real (siglos XIII-XV). In J. Torró \& E. Guinot Rodríguez (Eds.), Hidráulica agraria y sociedad feudal (pp. 103-146). València: Universitat de València.

Hernández Charro, M. C. (2006): Agua y poblamiento: Notas sobre la configuración del territorio de Tudela andalusí. Studia Historica. Historia Medieval, 24, 315-339.

Iglesies, J. (1991): El Fogatge de 1497: estudi i transcripció. Barcelona. Rafael Dalmau.

Kirchner, H. (1999): Migracions, assentaments pagesos, espais agrícoles i l'arqueologia d'alAndalus a Catalunya. In M. Barceló (Ed.), Musulmans i Catalunya (pp. 113-142). Barcelona: Empúries.

Kirchner, H., \& Navarro, C. (1993): Objetivos, método y práctica de la arqueología hidráulica. Archeologia Medievale, (XX), 121-150.

Kirchner, H., Vela, S., \& Oliver, J. (2002): Aigua probibida. Arqueologia bidràlica del feudalisme a Cerdanya: el Canal Reial de Puigcerdà. Bellaterra: Universitat Autònoma de Barcelona.

Lladonosa i Pujol, J. (1974): Història de Lleida. Tàrrega: F. Camps Calmet.

Monjo, M. (2012): La pervivencia del riego andalusí en la Aitona bajomedieval. In J. Torró \& E. Guinot (Eds.), Hidránica agraria y sociedad feudal. Prácticas, técnicas, espacios. (pp. 207-224). València: Publicacions de la Universitat de València.

P.P.S. (1945): Testamento de Jaume Sarroca, Obispo de Huesca, ordenado en su Castillo y Villa de Torres de Segre (Lérida), 11 diciembre 1289. Ilerda, (IV), 21-34.

Panadès Marsellès, I., Escolà Pons, M., \& Bertran Roigé, P. (1983): Torres de Segre: panoràmica bistòrica (p. 284). Ajuntament de Torres de Segre.

Panadès, I., Escolà, M. y Capdevila, A. (1990): La Sèquia de Torres i el regatge al Baix Segre. Torres de Segre: Publicacions de l'Ateneu.

Pons i Guri, J. M. (1964): Un fogatjament desconegut de l'any 1358 (p. 176). Barcelona: Real Academia de Buenas Letras de Barcelona.

Puy, A., Balbo, A. L., Virgili, A. y Kirchner, H. (2014): The evolution of Mediterranean wetlands in the first millennium AD: The case of Les Arenes floodplain (Tortosa, NE Spain). Geoderma, 232-234, 219-235.

Sabaté, F. (1998): La castralització de l'espai en l'estructuració d'un territori conquerit (Urgell, Pla d'Urgell, Garrigues i Segrià). Urtx, 11, 7-40.

Sarobe Huesca, R. (2011): Història de Rosselló de Segrià. Lleida: Pagès

Sarobe i Huesca, R. (1998): Col-lecció diplomàtica de la Casa del Temple de Gardeny: 1070-1200. Diplomataris. Barcelona: Fundació Noguera. 
Sitjes, E. (2006): Inventario y tipología de sistemas hidráulicos de al-Andalus. Arqueología Espacial, (26), 263-291.

Sol, R. y Torres, M. del C. (1974): Historia de un canal: 1147/1974. Los autores. Lleida

Teira Vilar, F. J. (1977): El régimen jurídico de aguas en el llano de Lleida (Siglos XII a XVIII). Barcelona: Universitat de Barcelona.

Virgili, A. (2010): Gent nova. La colonització feudal de la Catalunya Nova (segles XII-XIII). Butlletí de La Societat Catalana d'Estudis Històrics, (21), 77-102. 